\title{
pH-Induced Structural Changes of a Polymer Micelle Composed of Amphiphilic Polyallylamine Containing Hydrophilic Poly(L-glutamic acid) in the Side Chain
}

\author{
Masahiro HiguchI \\ Department of Organic Materials, National Institute of Materials and Chemical Research, \\ 1-1, Higashi, Tsukuba, Iharaki 305-8565, Japan
}

(Received September 3, 1998)

\begin{abstract}
An amphiphilic polymer composed of polyallylamine containing 7 mol\% hydrophobic palmitoyl groups and $92 \mathrm{~mol} \%$ hydrophilic poly(L-glutamic acid) grafted chains whose molecular weight was 4090 in the side chains was prepared. The amphiphilic polymers formed a stable and globular micelle in aqueous solution at $\mathrm{pH}$ above 4.0 . We investigated $\mathrm{pH}$-induced changes in the micellar structure of the amphiphilic polymer in the aqueous solution. The grafted poly $(\mathrm{L}-\mathrm{glutamic}$ acid) chains of the amphiphilic polymer showed $\mathrm{pH}$-dependence conformational transition $(\beta$ sheet $\rightarrow \alpha$-helix and random coil $\rightarrow$ random coil). Conformational changes of the grafted polypeptides chains regulated the surface polarity of the micelle composed of amphiphilic polymer.

KEY WORDS Amphiphilic Polymer/Hydrophilic Polypeptide Side Chain/pH-Induced Conformational Change / Micelle / Surface Polarity /
\end{abstract}

Self-organization of biological molecules such as proteins, polysaccharides, or DNA closely related to the biological functions of the systems is well-known. Stimuli-induced structural changes of the systems regulate biological functions. Recently, self-assembly of artificial amphiphiles such as surfactant ${ }^{1-7}$ and amphiphilic polymer, ${ }^{8-16}$ which form aggregates like micelle, emulsions, vesicle, monolayer and bilayer, have been studied, and these amphiphiles make possible the building of a biomimetic functional structure. ${ }^{17-21}$ Assemblies of various amphiphiles have been studied for application in the recognition and separation of proteins, and controlled release of drugs in biotechnology and medicine. Sunamoto et al..$^{22-24}$ reported that the cholesterol-bearing pullulan formed stable and monodisperse self-aggregates. Self-aggregates complex with various hydrophobic substances and even with various soluble proteins such as $\alpha$-chymotrypsin and bovine serium albumin. Kono et al. ${ }^{25-27}$ reported the temperaturesensitive dioleoylphosphatidylethanolamine vesicle bearing poly $(N$-isopropylacrylamide-co-octadecylacrylate). They showed temperature-controlled release of the vesicle.

A previous study reported ${ }^{28}$ photo- and thermo-induced changes in the aggregate structures of photoresponsive amphiphilic polypeptides in aqueous solution. The polypeptide consisted of two amphiphilic $\alpha$-helical rods that were hydrophilic on one face and hydrophobic on the opposite side joined by an azobenzene. The polypeptides formed micellar aggregates in aqueous solution and hydrophobic compounds were incorporated into the interior of the micelle in the dark. Photo-induced high-order structural changes of the micelle resulted in the release of hydrophobic compounds into the external aqueous phase.

This paper reports surface polarity control of the micelle composed of polyallylamine having hydrophobic palmitoyl groups and hydrophilic poly(L-glutamic acid) graft chains in the side chain. The amphiphilic polymer formed stable and globular micelles in aqueous solution at $\mathrm{pH}$ above 4.0. The surface polarity of the micelle could be controlled by the $\mathrm{pH}$ induced conformational changes of the grafted poly(L-glutamic acid) chains.

\section{EXPERIMENTAL}

\section{Materials}

Polyallylamine (PAA, $M_{n}=10000$, purchased from Nittobo Co., Ltd.) incorporated with hydrophobic palmitoyl groups (PAAP) was synthesized by coupling reaction between PAA and palmitoyl chloride. PAA $(18.7 \mathrm{~g})$ was dissolved in $1 \mathrm{M} \mathrm{NaOH}$ aqueous solution $(200 \mathrm{~mL})$. The solution was stirred and palmitoyl chloride $(5.5 \mathrm{~g})$ was gradually added. The solution was stirred for $6 \mathrm{~h}$ at room temperature. After the reaction, $\mathrm{pH}$ of the solution was adjusted to 10.0 with $\mathrm{NaOH}$ aqueous solution, and the solution was dialyzed overnight against Milli-Q treated and doubly distilled water using a Spectra/Por molecular porous membrane tube (Spectrum Medical Industries Inc., MWCO: 3500 ) at $50^{\circ} \mathrm{C}$. After dialysis, the solution was lyophilized to obtain PAAP. Palmitoyl group content in PAAP was $7 \mathrm{~mol} \%$ from quantitation of non-reacted amino groups in PAAP by fluorescence ${ }^{9}$ using 4-fluoro-7-nitrobenzofurazan (NBD) as probe. NBD, which is nonfluorescent, rapidly reacts with primary amino groups to yield useful probes that fluoresce.

PAAP with a small amount of 2-pyridyl-disulfide groups, the reactive sites, ${ }^{30}$ in the side chain (PSPAAP) was obtained as follows. PAAP $(10 \mathrm{~g})$ was dissolved in distilled water $(200 \mathrm{~mL})$ and $\mathrm{pH}$ of the solution was adjusted to 8.0. $\mathrm{N}$-Sccinimidyl-3(2-pyridyldithio)propionate $(0.3 \mathrm{~g})$ was added to the solution, which was stirred for $3 \mathrm{~h}$ at room temperature. After the reaction, the solution was dialyzed overnight at room temperature and lyophilized. 2-pyridyl-disulfide group content in PSPAAP was $1 \mathrm{~mol} \%$ from absorbance at $275 \mathrm{~nm}$ on the basis of the molar extinction coefficient of the pyridyl group in PSPAAP $N, N$-dimethylformamide.

The introduction of grafted poly(L-glutamic acid) chains to PSPAAP was carried out as follows. Grafted poly $(\gamma$-methyl L-glutamate) chains were synthesized by 


\begin{tabular}{|c|c|c|}
\hline \multicolumn{3}{|c|}{$\left.+\mathrm{CH}_{2}-\mathrm{CH}\right)\left(\mathrm{CH}_{2}-\mathrm{CH}\right)\left(\mathrm{CH}_{2}-\mathrm{CH}\right)$} \\
\hline $\mathrm{CH}_{2}$ & $\mathrm{CH}_{2}$ & \\
\hline NH & $\mathrm{NH}$ & $\mathrm{NH}$ \\
\hline $\mathrm{CO}$ & $\left(\mathrm{CH}_{2}\right)_{14}$ & $t_{0}^{1}$ \\
\hline $\begin{array}{l}\mathrm{CH}_{2} \\
\mathrm{CH}\end{array}$ & $\mathrm{CH}_{3}$ & $\left.\mathrm{C} H+\mathrm{CH}_{2}\right)_{2}-\mathrm{COOH}$ \\
\hline SH & & \\
\hline $1 \%$ & $7 \%$ & $92 \%, P n=32$ \\
\hline
\end{tabular}

Scheme 1. SPAAPPE.

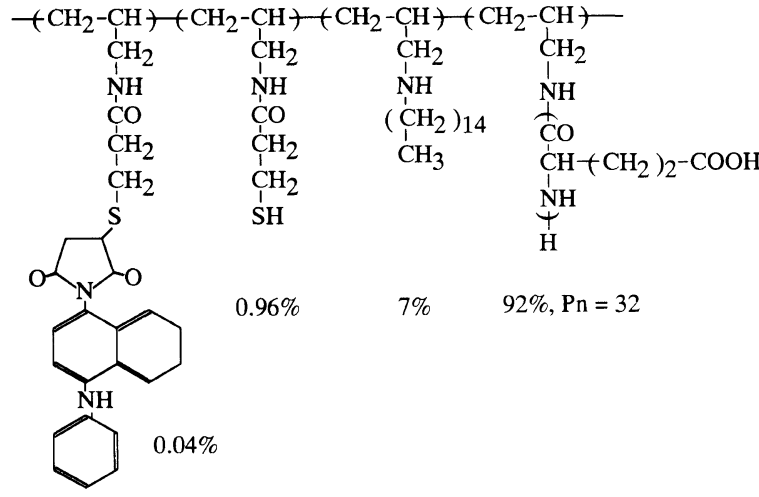

Scheme 2. AN-SPAAPPE.

polymerization of $\mathrm{N}$-carboxyanhydride of L-glutamic acid $\gamma$-methyl ester ${ }^{31}(2 \mathrm{~g})$ in $N, N$-dimethylformamide solution $(100 \mathrm{~mL})$ with PSPAAP $(40 \mathrm{mg})$ as initiator. The polymerization occurred at room temperature over $24 \mathrm{~h}$. The hydrophilic poly(L-glutamic acid) graft chain was obtained by saponification of the grafted poly $(\gamma$-methyl L-glutamate) chain. After the reaction, the solution was dialyzed overnight at room temperature and lyophilized. The degree of polymerization of the grafted poly(Lglutamic acid) chain was 32 from quantitation of terminal amino groups of the polymer by fluorescence as above. The polymer obtained $(0.5 \mathrm{~g})$ was dissolved in aqueous solution containing $25 \mathrm{mM}$ dithiothreitol at $\mathrm{pH} 4.5$ and stirred over $24 \mathrm{~h}$ at room temperature. ${ }^{32}$ After the reaction, the solution was dialyzed overnight to remove dithiothreitol and pyridine-2-thione, and lyophilized to obtain the amphiphilic polymer which had $7 \mathrm{~mol} \%$ palmitoyl group, $92 \mathrm{~mol} \%$ hydrophilic poly(L-glutamic acid) graft chain, and $1 \mathrm{~mol} \%$ thiol group in the side chain (SPAAPPE, Scheme 1).

SPAAPPE with a small amount of anilinonaphthalene in the side chain (AN-SPAAPPE, Scheme 2) was prepared to estimate the surface polarity of the micelle by fluorescence analysis. The emission maxima of anilinonaphthalene derivatives are strongly dependent on polarity around the probe. ${ }^{33}$ SPAAPPE $(0.1 \mathrm{~g})$ was dissolved in aqueous solution $(100 \mathrm{~mL})$ at $\mathrm{pH} 7.5$ and incubated at $0^{\circ} \mathrm{C}$ with $20 \mathrm{~mL}$ ethanol solution of $N$ (1-anilinonaphthyl-4)-maleimide $(1 \mathrm{mM})$ for $1 \mathrm{~h} .{ }^{34}$ The solution was then dialyzed overnight and lyophilized to obtain AN-SPAAPPE. Anilinonaphthalene group content, $0.04 \mathrm{~mol} \%$, in AN-SPAAPPE was determined from fluorescence intensity at $425 \mathrm{~nm}$ (excitation wavelength: $348 \mathrm{~nm}$ ) of $N, N$-dimethylformamide solution of $\mathrm{AN}$ SPAAPPE on the basis of fluorescence intensity-concentration of anilinonaphthalene monomer in $N, N$ dimethylformamide.

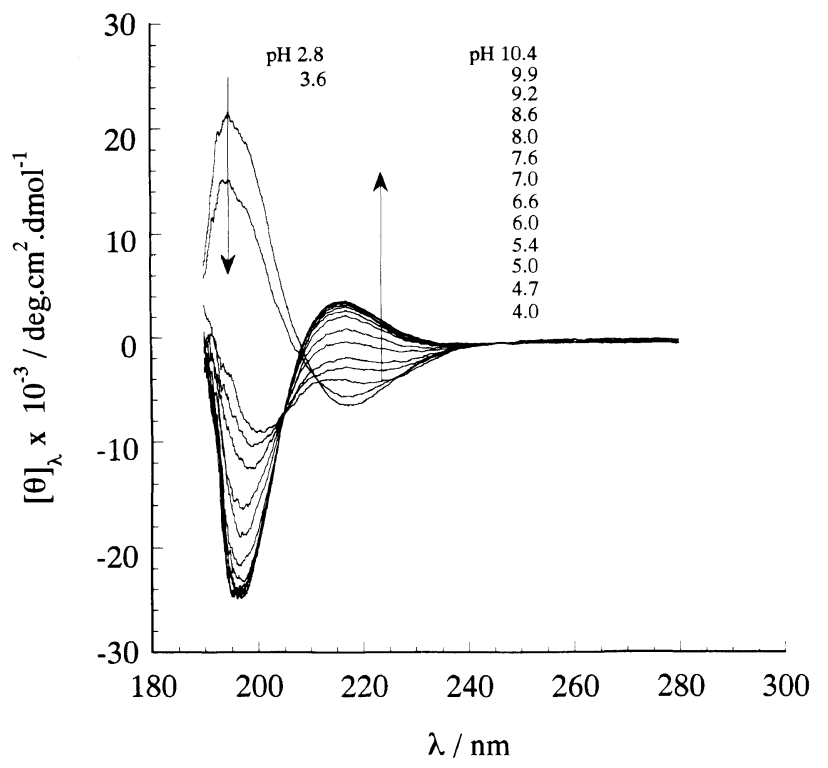

Figure 1. CD spectra of SPAAPPE in aqueous solution containing $50 \mathrm{mM} \mathrm{NaCl}$ at various $\mathrm{pHs}$.

\section{Methods}

Preparation of SPAAPPE Micelle. SPAAPPE was dispersed in aqueous solution containing $50 \mathrm{mM} \mathrm{NaCl}$ at various $\mathrm{pH}$, and sonicated in an ice-water bath under a stream of nitrogen using an ultrasonic processor (Branson Sonifier Model 250) for $10 \mathrm{~min}$. The concentration of SPAAPPE in the aqueous solution was fixed at $0.1 \mathrm{mg} \mathrm{mL}^{-1}$

Formation of the micellar structure of SPAAPPE was followed by incorporation of the hydrophobic fluorescence probe, anilinonaphthalene, into the micelle. Fluorescence spectra of anilinonaphthalene in SPAAPPE aqueous solution at various $\mathrm{pH}$ were measured with a spectrofluorophotometer (JASCO FP-777). Anilinonaphthalene was fixed at $1.0 \times 10^{-5} \mathrm{M}$. The excitation wavelength was $348 \mathrm{~nm}$.

Dynamic Light-Scattering Measurements. The size and distribution of the aggregate of SPAAPPE in aqueous solution containing $50 \mathrm{mM} \mathrm{NaCl}$ at various $\mathrm{pH}$ were measured at $25^{\circ} \mathrm{C}$ with a dynamic light scattering spectrophotometer (Otsuka Electronics Co., Ltd., DLS700).

Atomic Force Microscopic Measurements. The shape of the aggregate of SPAAPPE was observed with an atomic force microscope (AFM, Digital Instruments, Inc., Nanoscope IIIa) in the tapping mode. An aliquot of SPAAPPE aqueous solution containing $50 \mathrm{mM} \mathrm{NaCl}$ at various $\mathrm{pH}$ was placed on freshly cleaved mica, allowing the aggregate to be absorbed into the surface for $5 \mathrm{~min}$ at room temperature, rinsed with Milli-Q treated and doubly distilled water to remove excess salt and dried under ambient conditions. AFM images were taken in the "height" mode using silicon cantilevers $(125 \mathrm{~mm}$, tip radius $5-10 \mathrm{~nm})$. A $10 \mu \mathrm{m}$ by $10 \mu \mathrm{m}$ scanner was used for imaging.

Circular Dichroism Measurements. Circular dichroism spectra of SPAAPPE in $50 \mathrm{mM} \mathrm{NaCl}$ aqueous solution at various $\mathrm{pH}$ were measured with a JASCO J-700 WI spectropolarimeter. The secondary structure of the grafted poly(L-glutamia acid) chain was found from 


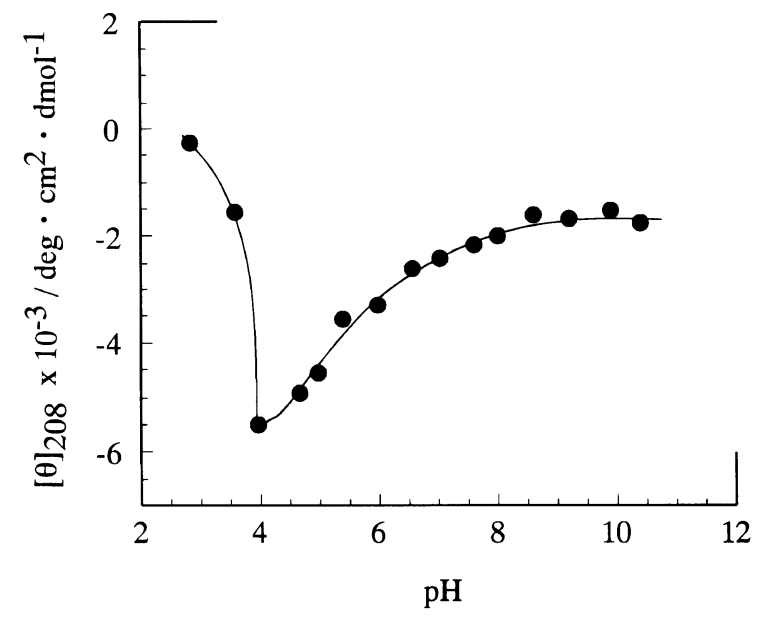

Figure 2. $\mathrm{pH}$ dependence of molar ellipticity at $208 \mathrm{~nm},[\theta]_{208}$, of SPAAPPE in aqueous solution containing $50 \mathrm{mM} \mathrm{NaCl}$.

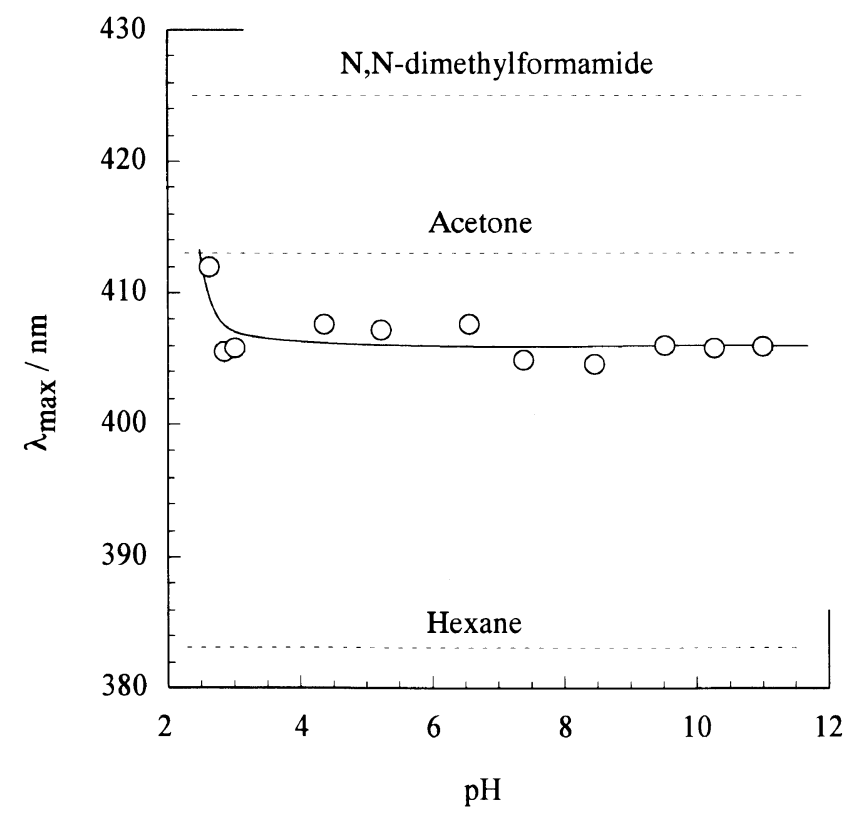

Figure 3. $\mathrm{pH}$ dependence of fluorescent emission maxima, $\lambda_{\max }$, of anilinonaphthalene in SPAAPPE aqueous solution containing $50 \mathrm{mM}$ $\mathrm{NaCl}$.

molar ellipticity, $[\theta]_{\lambda}$.

Surface Polarity Measurements of SPAAPPE Micelle. Surface polarity of the SPAAPPE micelle in aqueous solution containing $50 \mathrm{mM} \mathrm{NaCl}$ at various $\mathrm{pH}$ was followed by measuring emission maxima of AN-SPAAPPE. The excitation wavelength of AN-SPAAPPE was $348 \mathrm{~nm}$.

\section{RESULTS AND DISCUSSION}

\section{Conformation of Grafted Poly(L-glutamic acid) Chains of SPAAPPE}

The amphiphilic polymer, SPAAPPE, was mostly soluble in aqueous solution with $\mathrm{pH}$ above 2, giving slightly turbid solution. Conformations of grafted poly(L-glutamic acid) chains of SPAAPPE were characterized using circular dichroism (CD). CD spectra of grafted poly(L-glutamic acid) chains of SPAAPPE in aqueous solution at various $\mathrm{pH}$ are shown in Figure 1.

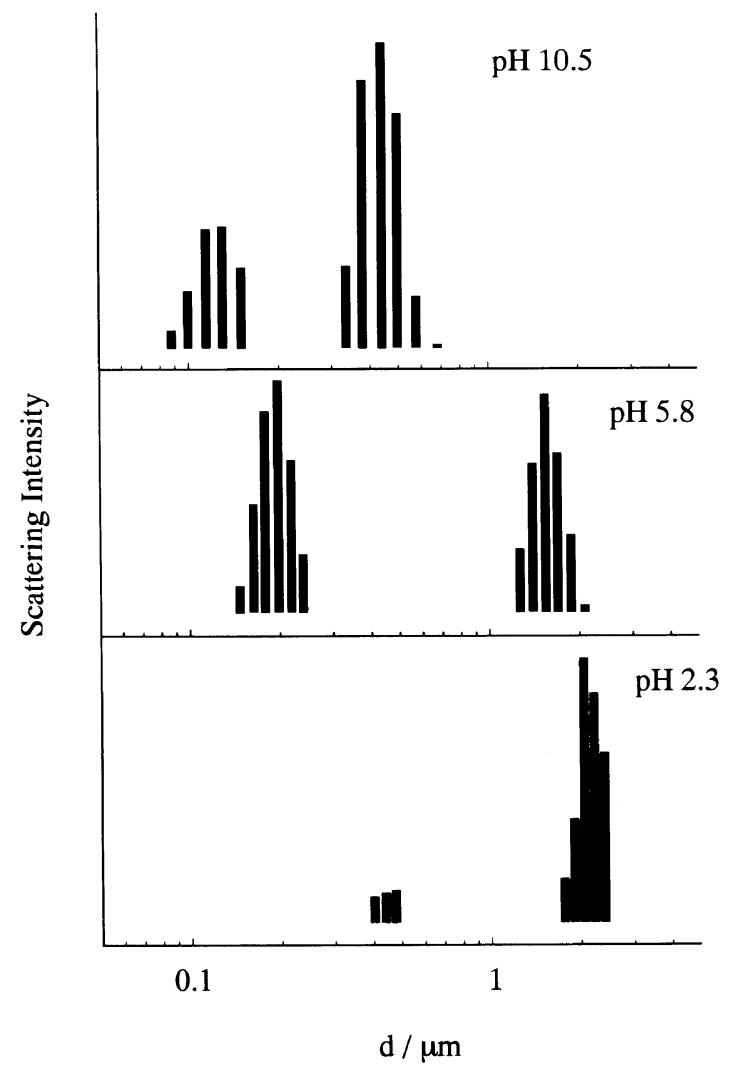

Figure 4. Histogram of particle size of the aggregate composed of SPAAPPE in aqueous solution containing $50 \mathrm{mM} \mathrm{NaCl}$ at $\mathrm{pH} 2.3, \mathrm{pH}$ 5.8 , and $\mathrm{pH} 10.5$.

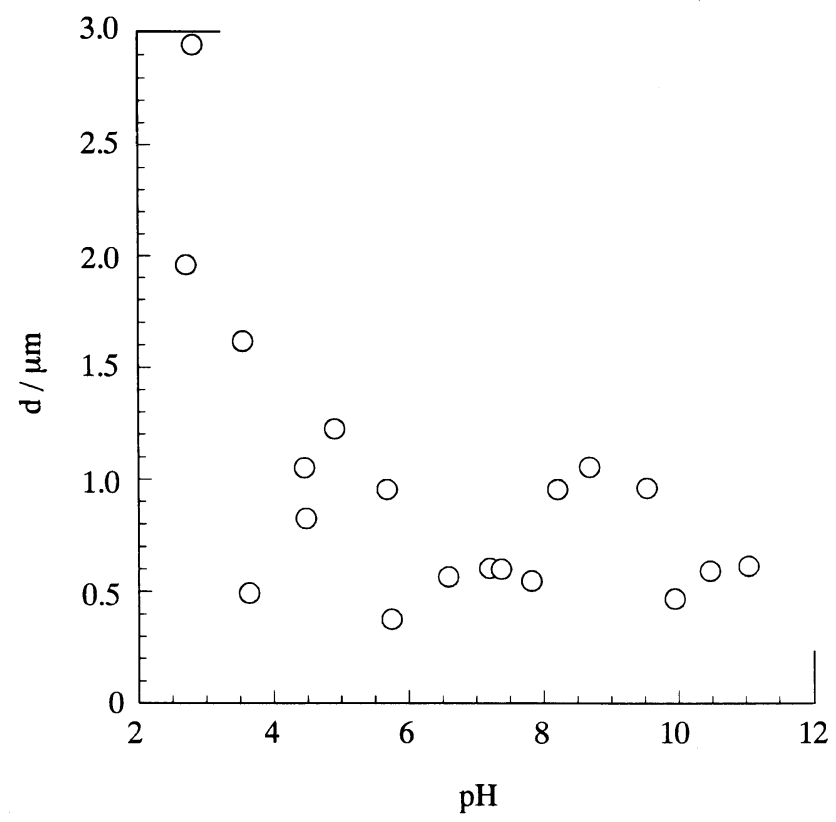

Figure 5. $\mathrm{pH}$ dependence of average particular size, $d$, of SPAAPPE in aqueous solution containing $50 \mathrm{mM} \mathrm{NaCl}$.

CD spectra of SPAAPPE aqueous solution at $\mathrm{pH} 2.8$ and 3.6 exhibited a negative band at $217 \mathrm{~nm}$ and positive band at $195 \mathrm{~nm}$ typical of $\beta$-sheet. ${ }^{35} \mathrm{CD}$ spectra of SPAAPPE at $\mathrm{pH}$ above 4.0 showed remarkable distortion. The negative band at $222 \mathrm{~nm}$ at $\mathrm{pH} 4.0$ indicated the grafted poly(L-glutamic acid) chains to be in an $\alpha$ helix structure. Molar ellipticity of $222 \mathrm{~nm}$ decreased with $\mathrm{pH}$, and the spectrum with a positive band at $217 \mathrm{~nm}$, 
(a) $\mathrm{pH} 3.0$
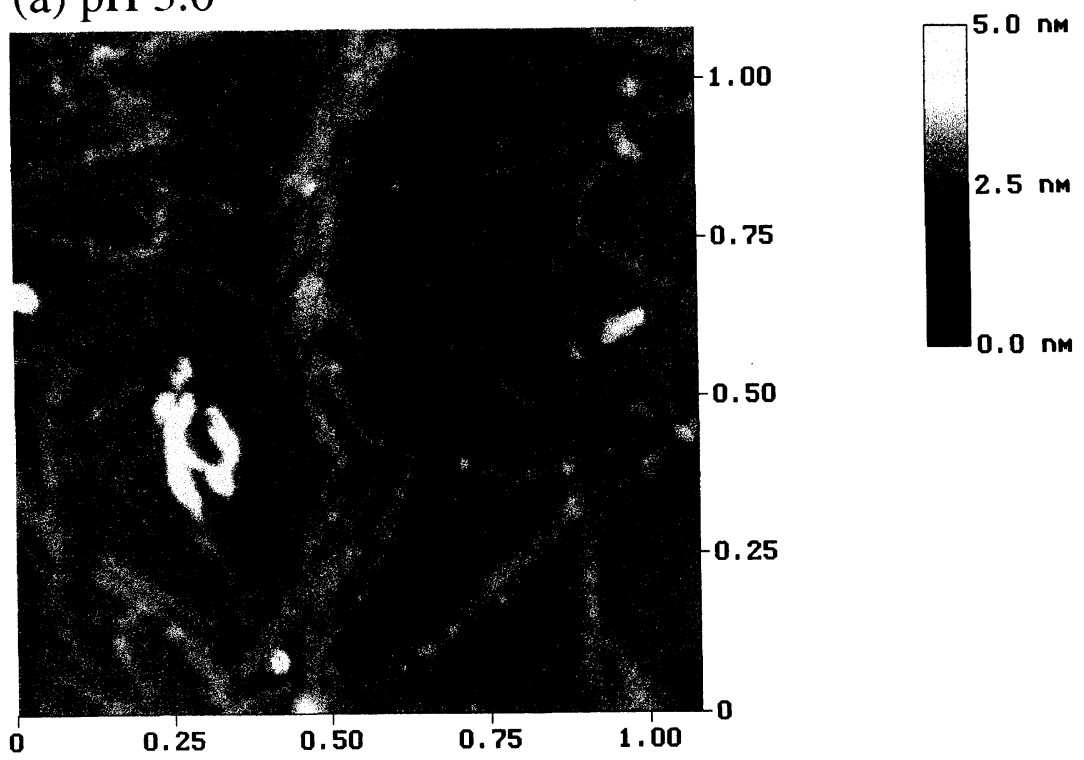

\section{(b) $\mathrm{pH} 8.0$}
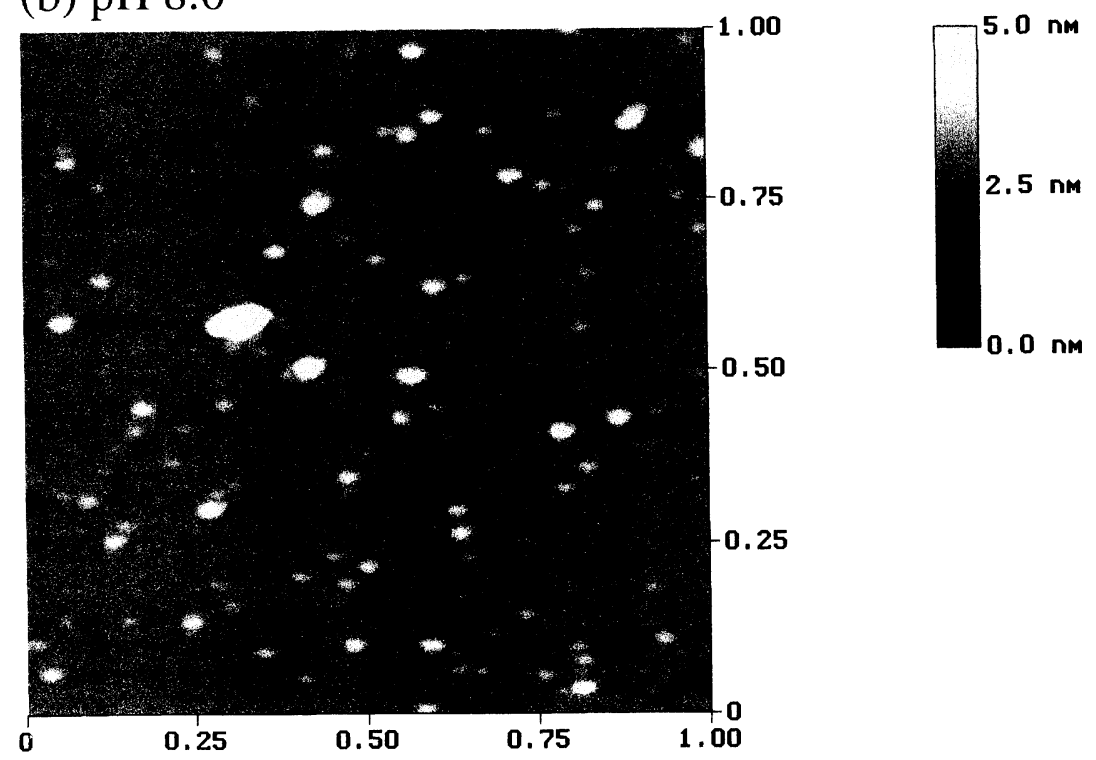

Figure 6. Typical AFM images of SPAAPPE aggregate in aqueous solution containing $50 \mathrm{mM} \mathrm{NaCl}$ at pH 3.0 (a) and pH 8.0 (b).

associated with the random coil structure, was observed above $\mathrm{pH}$ 6.0.

Figure 2 shows $\mathrm{pH}$ dependence of molar ellipticity of the CD band at $208 \mathrm{~nm},[\theta]_{208}$, associated with $\alpha$-helix content, of grafted poly(L-glutamic acid) chains of SPAAPPE in aqueous solution. $[\theta]_{208}$ was zero when poly(amino acid) has a $\beta$-sheet structure. In the low $\mathrm{pH}$ region below $\mathrm{pH} 4.0$, the grafted poly(L-glutamic acid) chains of SPAAPPE formed $\beta$-sheets owing to the intermolecular interaction of protonated poly(L-glutamic acid) graft chains. Partial ionization of the grafted poly(L-glutamic acid) chains weakened intermolecular interactions, resulting in formation of the $\alpha$-helix structure in SPAAPPE. Further ionization of the Lglutamic acid moieties of the grafted chains above $\mathrm{pH}$ 4.0 induced electrostatic repulsion force among charged moieties, so that the $\alpha$-helix structure of grafted poly(L-glutamic acid) chains of SPAAPPE underwent conformational transition to a random coil.

\section{Micellization of SPAAPPE}

The micellization of the SPAAPPE was estimated from the incorporation of the fluorescent probe, anilinonaphthalene, into the hydrophobic interior of the SPAAPPE micelle. The emission maximum, $\lambda_{\max }$, of anilinonaphthalene is very sensitive to environmental polarity around the probe, and shifts to higher wavelength with increase in environmental polarity. Figure 3 shows $\mathrm{pH}$ dependence of $\lambda_{\max }$ of anilinonaphthalene in SPAAPPE aqueous solution, along with plots of $\lambda_{\max }$ of anilinonaphthalene in $N, N$-dimethylformamide, acetone and hexane. Environmental polarity of anilinonaphthalene in the SPAAPPE aqueous solution corresponded to that between acetone and hexane in the experimental $\mathrm{pH}$ region. $\lambda_{\max }$ of anilinonaphthalene in SPAAPPE aqueous solution reached equilibrium and a 
relative low value, $406 \mathrm{~nm}$, at $\mathrm{pH}$ above 4.0. Emission at $406 \mathrm{~nm}$ implies that anilinonaphthalene is incorporated into the hydrophobic region in SPAAPPE aqueous solution. This suggests that SPAAPPE forms stable micelle in aqueous solution when the grafted poly $(\mathrm{L}-$ glutamic acid) chains of SPAAPPE are in $\alpha$-helix and/or random coil conformation, and anilinonaphthalene is incorporated into the hydrophobic interior of the SPAAPPE micelle.

The size and distribution of the aggregate of SPAAPPE in aqueous solution were measured by dynamic light scattering. Figure 4 shows the histogram of a certain size of the SPAAPPE aggregate. SPAAPPE formed polydisperse aggregate in aqueous solution at experimental $\mathrm{pH}$. Increasing $\mathrm{pH}$ induces conformational change of grafted poly(L-glutamic acid) chains of SPAAPPE, and then the decrease of intermolecular interaction. This leads to the destruction of large aggregates and gives rise to the bimodal distribution of particle size. Average particular size, $d$, of SPAAPPE aggregate was calculated by cumulant analysis (Figure 5). $d$ decreased with $\mathrm{pH}$. A comparison between $\mathrm{pH}$ dependence of the grafted poly(L-glutamic acid) chain conformation (Figures 2 and 3 ) and that of $d$ (Figure 5) suggested that SPAAPPE formed bigger aggregates when the grafted poly $(\mathrm{L}-$ glutamic acid) chains of SPAAPPE had the $\beta$-sheet structure.

To determine the shape of the SPAAPPE aggregate in aqueous solution, observation with atomic force microscopy (AFM) was carried out. Typical AFM images of SPAAPPE aggregate in aqueous solution are shown in Figure 6. In the AFM image of SPAAPPE in aqueous solution at $\mathrm{pH} 3.0$ (Figure 6(a)), fibrous aggregates were clearly observed. The formation of fibrous aggregates may possibly be due to hydrogen bonds among grafted poly(L-glutamic acid) chains having the $\beta$-sheet structure. Globular particles could be seen in the image of the SPAAPPE micelle solution at $\mathrm{pH} 8.0$ (Figure 6(b)). The same globular particles could be observed in SPAAPPE micelle solution above $\mathrm{pH}$ 4.0. SPAAPPE may thus form stable and globular micelles when grafted poly(L-glutamic acid) chains of SPAAPPE are in $\alpha$ helix and/or random coil conformation above $\mathrm{pH} 4.0$.

\section{pH-Induced Surface Polarity Changes of SPAAPPE Micelle}

Surface polarity of the SPAAPPE micelle was studied by fluorescence using AN-SPAAPPE in which anilinonaphthalene was covalently introduced into the side chain of SPAAPPE (Scheme 2). The surface polarity of SPAAPPE micelle was found from the wavelength of emission maxima, $\lambda_{\max }$, of AN-SPAAPPE in the aqueous solution. $\lambda_{\text {max }}$ of AN-SPAAPPE in the experimental $\mathrm{pH}$ region shifted to a higher wavelength than that of $A N$ group in the hydrophobic interior of the SPAAPPE micelle, $406 \mathrm{~nm}$ (Figure 3). This implies that the labeled AN group exists in the interface between hydrophobic core composed of palmitoyl groups and hydrophilic grafted poly(L-glutamic acid) outer layer. The emission maxima of model compound, anilinonaphthalene modified polyallylamine (AN-PAA), in aqueous solution containing acetonitrile are plotted in Figure 7 . The surface polarity of SPAAPPE micelle could be controlled

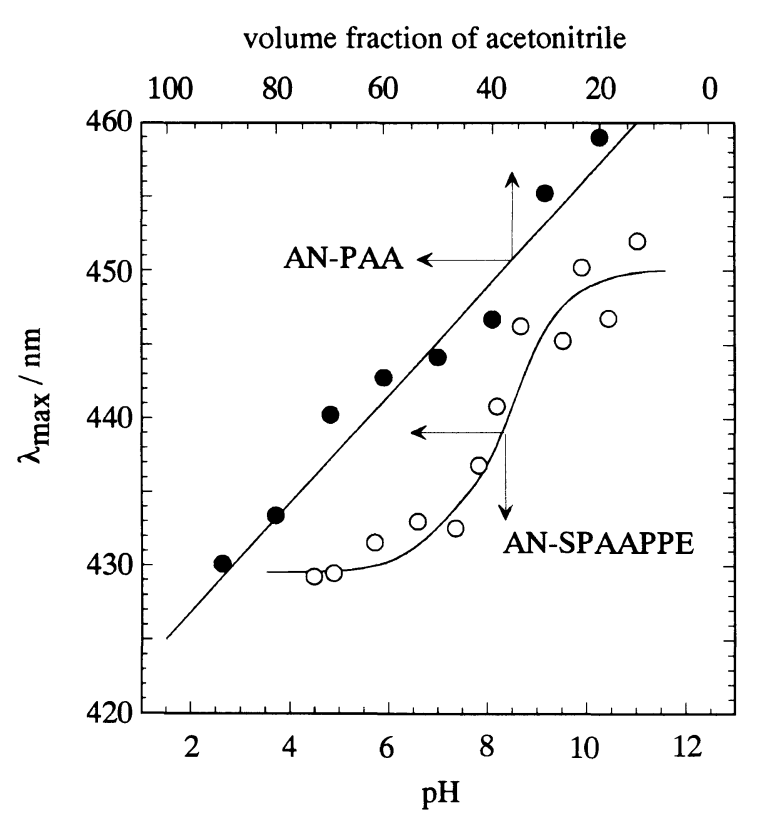

Figure 7. (O): $\mathrm{pH}$ dependence of fluorescent emission maxima, $\lambda_{\max }$ of AN-SPAAPPE in aqueous solution containing $50 \mathrm{mM} \mathrm{NaCl}$. (O) Relation between fluorescent emission maxima, $\lambda_{\max }$, of AN-PAA in aqueous solution containing acetonitrile and volume fraction of acetonitrile.

in the range of polarity corresponding to that between $90 \mathrm{vol} \%$ and $40 \mathrm{vol} \%$ of acetonitrile aqueous solution. $\lambda_{\max }$ of AN-SPAAPPE in aqueous solution was strongly dependent on $\mathrm{pH}$, i.e., the surface polarity of SPAAPPE micelle steeply increased with $\mathrm{pH}$ at $\mathrm{pH}$ 8.5. Above $\mathrm{pH}$ 8.5 , the grafted poly(L-glutamic acid) chain was mainly in the random coil conformation (Figure 2). Thus, $\mathrm{pH}$ response of surface polarity of the micelles closely correlated with the conformational behavior of grafted poly(L-glutamic acid) chain. The inflection point on $\mathrm{pH}$ dependence of $\lambda_{\max }$ of AN-SPAAPPE was at $\mathrm{pH}$ higher than that of the conformational transition. Anilinonaphthalene was located in the interface of the hydrophobic core composed of palmitoyl groups and the hydrophobic poly(L-glutamic acid) layer, so that polarity changes monitored by anilinonaphthalene reflect overall conformational changes of the poly(L-glutamic acid) layer of the micelle.

\section{REFERENCES}

1. K. Yamada, H. Ihara, T. Ide, and T. Fukumoto, Chem. Lett., 1713 (1984)

2. N. Nakashima, S. Asakawa, and T. Kunitake, J. Am. Chem. Soc., 107, 509 (1985)

3. H. Ihara, T. Fukumoto, C. Hirayama, and R. Yamada, Polym. Commun., 27, 282 (1986)

4. J. H. Furhop, P. Schnieder, E. Boekma, and W. Helfrich, J. Am. Chem. Soc., 110, 2861 (1988).

5. T. Imae, Y. Takahashi, and H. Muramatu, J. Am. Chem. Soc., 114, 3414 (1992)

6. J. H. Furhop, D. Spiroski, and C. Boettcher, J. Am. Chem. Soc., 115, 1600 (1993).

7. T. Shimizu, M. Kogiso, and M. Masuda, Nature, 383, 487 (1996)

8. H. Morii, K. Ichimura, and H. Uedaira, Chem. Lett., 1987 (1990).

9. M. Higuchi, A. Takizawa, T. Kinoshita, Y. Tsujita, and K. Okochi, Macromolecules, 23, 361 (1990).

10. M. Mutter, G. Tuchschever, C. Miller, K. H. Altmann, R. I. Carey, D. F. Wyss, A. M. Labhardt, and J. E. Rivier, J. Am. Chem. Soc., 114, 1463 (1992). 
11. T. M. Chin, K. D. Berndt, and N. C. Yang, J. Am. Chem. Soc., 114, 2279 (1992).

12. M. R. Ghadiri, J. R. Granja, R. A. Milligan, D. E. McRee, and N. Khazanovich, Nature, 366, 324 (1993).

13. J. D. Hartgerink, J. R. Granja, R. A. Milligan, and M. R. Ghadiri, J. Am. Chem. Soc., 118, 43 (1996).

14. A. Toyotama, S. Kugimiya, M. Yonese, T. Kinoshita, and Y. Tsujita, Chem. Lett., 443 (1997).

15. H. Hosokawa, T. Kinoshita, Y. Tsujita, and H. Yoshimizu, Chem. Lett., 745 (1997).

16. M. Higuchi, N. Minoura, and T. Kinoshita, Langmuir, 13, 1616 (1997).

17. K. W. Hahn, W. A. Klis, and J. M. Stewart, Science, 248, 1544 (1990).

18. M. R. Ghadiri, J. R. Granja, and L. K. Buehler, Nature, 369, 301 (1994).

19. M. Higuchi, N. Minoura, and T. Kinoshita, Macromolecules, 28 , 4981 (1995).

20. T. Kinoshita, Prog. Polym. Sci., 20, 527 (1995).

21. F. Rabanal, W. F. DeGrado, and P. L. Duffon, J. Am. Chem. Soc., 118, 473 (1996).

22. T. Nishikawa, K. Akiyoshi, and J. Sunamoto, J. Am. Chem. Soc., 118, 6110 (1996).
23. K. Akiyoshi, S. Deguchi, H. Tajima, T. Nishikawa, and J. Sunamoto, Macromolecules, 30, 857 (1997).

24. K. Akiyoshi, Y. Sasaki, K. Kuroda, and J. Sunamoto, Chem. Lett., 93 (1998).

25. K. Kono, H. Nishii, and T. Takagishi, Biochem. Biophys. Acta, 1164, 81 (1993).

26. K. Kono, K. Zenitani, and T. Takagishi, Biochem. Biophys. Acta, 1193, 1 (1994)

27. H. Hayashi, K. Kono, and T. Takagishi, Biochem. Biophys. Acta, 1280, 127 (1996).

28. M. Higuchi and T. Kinoshita, J. Photochem. Photobiol. B: Biol., 42, 143 (1998)

29. T. Toyooka, Y. Watanabe, and K. Imai, Anal. Chem. Acta, 149, 305 (1983).

30. P. Walden, Z. A. Nagy, and J. Klein, J. Mol. Cell Immunol., 2, 191 (1986).

31. W. H. Daly and D. Poche, Tetrahedron Lett., 29, 5859 (1988).

32. J. Carlsson, H. Drevin, and R. Axen, Biochem. J., 173, 723 (1978).

33. G. K. Radda, Biochem. J., 122, 385 (1971).

34. Y. Kanaoka, M. Machida, M. Machida, and T. Sekine, Biochem. Biophys. Acta, 351, 214 (1974).

35. N. Greenfield and G. Fasman, Biochemistry, 8, 4108 (1969). 